\title{
One-stop hybrid coronary revascularization versus off-pump coronary artery bypass in patients with diabetes mellitus
}

\author{
Zhizhao Song, MD, ${ }^{\mathrm{a}}$ Liuzhong Shen, MD, ${ }^{\mathrm{a}}$ Zhe Zheng, MD, ${ }^{\mathrm{a}}$ Bo Xu, MD, ${ }^{\mathrm{b}}$ Hui Xiong, MD, ${ }^{\mathrm{a}}$ \\ Lihuan $\mathrm{Li}, \mathrm{MD},{ }^{\mathrm{c}}$ and Shengshou $\mathrm{Hu}, \mathrm{MD}^{\mathrm{a}}$
}

\section{ABSTRACT}

Objectives: To compare in-hospital and midterm outcomes after one-stop hybrid coronary revascularization (HCR) and off-pump coronary artery bypass $(\mathrm{OPCAB})$ in patients with diabetes mellitus (DM).

Methods: The series included 120 patients with DM who underwent one-stop HCR at Fuwai Hospital between June 2007 and September 2014. These patients were 1:2 matched with 240 patients who underwent OPCAB using propensity score matching. The primary endpoint was a major adverse cardiac or cerebrovascular event (MACCE) over midterm follow-up, and secondary endpoints were in-hospital outcomes. Accounting for matched-pairs design, the survival analysis was evaluated with a marginal Cox model, and the continuous and dichotomous variables of in-hospital outcomes were compared with the Wilcoxon signed-rank test and a logistic regression model using generalized estimating equations, respectively.

Results: Compared with OPCAB, one-stop HCR was associated with less chest tube drainage (median, $748 \mathrm{~mL}$ [interquartile range (IQR), 540-1080 mL] vs $990 \mathrm{~mL}$ [IQR, 730-1250 mL]; $P<.001$ ), a lower packed red blood cell transfusion rate $(18.3 \%$ vs $29.6 \% ; P=.032)$, shorter mechanical ventilation time (median, 13.7 hours [IQR, 10.3-16.9 hours] vs 16.8 hours [IQR, 13.0-19.6 hours]; $P<.001$ ), and shorter stay in intensive care unit (median 21.7 hours [IQR, 19.0-44.3 hours] vs 46.7 hours [IQR, 24.3-72.7 hours]; $P<.001$ ). Over 30 months of follow-up, one-stop HCR and OPCAB had a similar rate of MACCE $(7.4 \%$ vs $8.0 \%$ at 3 years; hazard ratio, $0.807 ; 95 \%$ confidence limit, $0.352-1.849$; $P=.612)$, but one-stop HCR had a lower stroke rate $(0 \%$ vs $3.6 \%$ at 3 years; $P=.046)$.

Conclusions: For selected patients with DM, one-stop HCR provided safe and reproducible revascularization, with less perioperative invasiveness and similar and favorable midterm outcomes compared with OPCAB. (J Thorac Cardiovasc Surg 2016;151:1695-701)

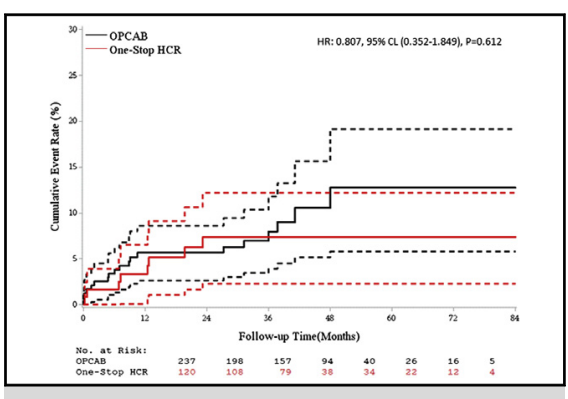

MACCE Kaplan-Meier curves, with number of patients at risk and $95 \%$ confidence limits.

\section{Central Message}

For selected patients with DM, one-stop hybrid coronary revascularization provided a safe and reproducible revascularization option.

\section{Perspective}

Hybrid coronary revascularization (HCR) combines the advantage of both CABG and PCI to achieve complete revascularization. In selected patients with $\mathrm{DM}$ and multivessel CAD, the results of this study show that one-stop HCR decreased perioperative invasiveness and incurred similar and favorable midterm outcomes compared with $\mathrm{OPCAB}$.

See Editorial Commentary page 1702.

\footnotetext{
From the Departments of ${ }^{\mathrm{a}}$ Surgery, ${ }^{\mathrm{b}}$ Cardiology, and ${ }^{\mathrm{c}}$ Anesthesiology, State Key Laboratory of Cardiovascular Disease, Fuwai Hospital, National Center for Cardiovascular Disease, Chinese Academy of Medical Sciences and Peking Union Medical College, Beijing, China.

Z.S. and L.S. contributed equally to this work.

This study was supported by the Key Project in the National Science and Technology Pillar Program during the 12th 5-Year Plan Period (2011BAI11B21).

Received for publication July 23, 2015; revisions received Jan 8, 2016; accepted for publication Jan 20, 2016; available ahead of print March 8, 2016.

Address for reprints: Shengshou Hu, MD, Department of Surgery, Fuwai Hospital, 167 Beilishi Rd, Xicheng District, Beijing 100037, China (E-mail: Shengshouhu@ yahoo.com).

$0022-5223 / \$ 36.00$

Copyright (c) 2016 by The American Association for Thoracic Surgery

http://dx.doi.org/10.1016/j.jtcvs.2016.01.049
}

One-quarter of coronary revascularization procedures are performed in patients with diabetes mellitus (DM). These patients present with accelerated atherosclerotic progression and increased platelet aggregation, which result in suboptimal outcomes compared with patients without

Scanning this QR code will take you to supplemental tables for this article.

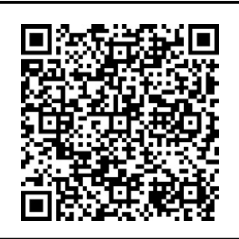




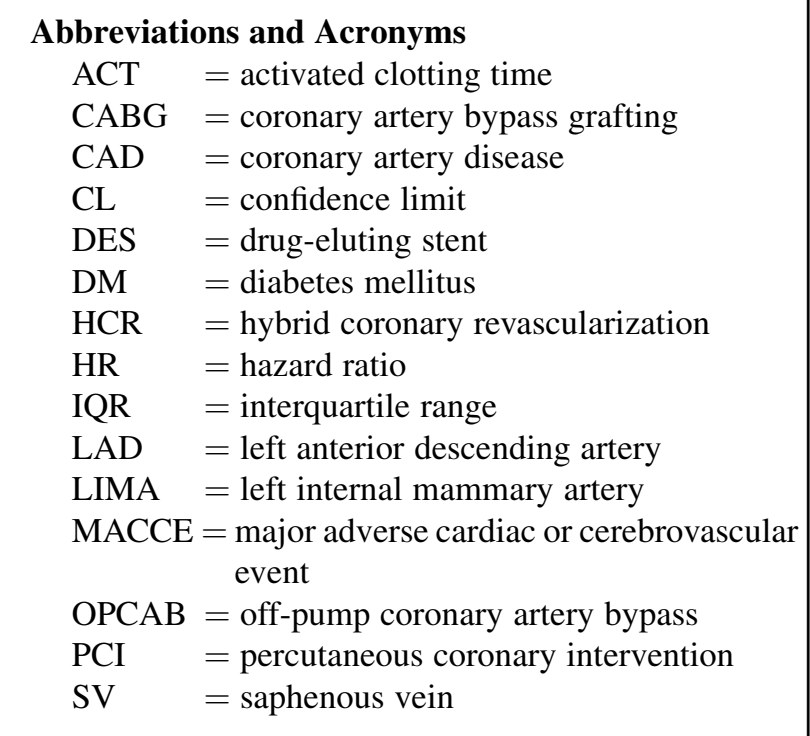

DM. ${ }^{1,2}$ A recent randomized clinical trial reported better survival with coronary artery bypass grafting (CABG) compared with percutaneous coronary intervention (PCI) for these patients. ${ }^{3}$ It is generally believed that the survival superiority of $\mathrm{CABG}$ is due mainly to the left internal mammal artery (LIMA) to left anterior descending artery (LAD) graft, based on its favorable long-term patency rate $(>90 \%$ at 10 years). ${ }^{4,5}$ However, the patency rate of saphenous vein (SV) grafts decreases year by year, from approximately $80 \%$ at 1 year to an average of $70 \%$ at 5 years. ${ }^{6,7}$ In addition, the use of drug-eluting stents (DES) has a lower target lesion revascularization rate compared with bare metal stents (approximately $5 \%$ vs $20 \%$ at 1 year and $10 \%$ vs $25 \%$ at 5 years) ${ }^{8,9}$ Thus, PCI with DES is hypothesized to be a promising treatment for non-LAD lesions. ${ }^{10}$

Hybrid coronary revascularization (HCR), involving minimally invasive LIMA-LAD grafting and PCI for nonLAD lesions, combines the advantage of both strategies to achieve complete revascularization. ${ }^{11}$ In initial experiences, HCR has produced favorable outcomes in selected patients with multivessel coronary artery disease (CAD). ${ }^{12,13}$ However, there are few published studies on the integrated revascularization strategy in patients with DM. In the present study, using propensity score matching, we compared in-hospital and midterm outcomes after one-stop HCR and off-pump coronary artery bypass $(\mathrm{OPCAB})$ in patients with DM.

\section{METHODS \\ Patient Selection}

Between June 2007 and September 2014, 120 patients with DM underwent one-stop HCR at Fuwai Hospital. During the same period, 1905 DM patients underwent OPCAB with LIMA-LAD grafting and SV to non-LAD grafting. After screening these patients with the exclusion criteria, the remaining patients $(n=1658)$ were subjected to propensity score matching (original data presented in Table E1). The patients undergoing one-stop HCR were then 1:2 matched with those undergoing OPCAB (Figure 1). This study was approved by the institutional Ethical Committee of Fuwai Hospital.

The inclusion criteria for one-stop HCR were (1) multivessel CAD involving LAD lesion (eg, chronic total occlusion, excessive tortuosity, severely diffuse lesion) or left main coronary artery lesion (unprotected) not favorable for PCI, with non-LAD lesions suitable for PCI, and (2) multivessel CAD with traditional CABG contraindications (eg, heavily calcified ascending aorta, lack of available graft conduits, non-LAD lesions impracticable to anastomosis but feasible for PCI, high-risk status for traditional CABG, such as dysfunction of vital organs). The exclusion criteria for one-stop HCR were (1) minimally invasive LIMA-LAD grafting contraindications (eg, previous sternotomy; LIMA or left subclavian artery stenosis; distal LAD impracticable to anastomosis, such as intramyocardial LAD; significantly unstable hemodynamics, such as mechanical support) and (2) concurrent with other cardiac surgery, for example, valve replacement.

Since 2007, a heart team consisting of 2 experienced interventional cardiologists and 2 experienced cardiac surgeons, had been set up in a cardiology ward at Fuwai Hospital. If a patient met the foregoing criteria, decisions regarding the optimal revascularization strategy were made by the heart team considering the patient's clinical condition, coronary anatomy, and individual needs.

For the patients who underwent OPCAB, the criteria for entering propensity score matching were (1) multivessel CAD involving LAD lesion or left main coronary artery lesion and (2) completion of a LIMA-LAD graft and an SV to non-LAD graft. Exclusion criteria were (1) concurrent with other cardiac surgery, (2) previous sternotomy, and (3) significantly unstable hemodynamics.

\section{Procedures}

One-stop HCR was performed in a hybrid operation room, involving minimally invasive LIMA-LAD grafting and consecutive PCI for non-LAD lesions. The procedure and the protocol for antiplatelet and anticoagulation therapy are outlined below.

Using a lift retractor, the LIMA pedicle was harvested under direct vision through reversed-L inferior sternotomy, and its distal end was anastomosed to LAD in situ with off-pump techniques. Transit time flow measurement was routinely performed when the anastomosis was completed. After the surgical operation, instant angiography to confirm the LIMA-LAD graft patency and PCI for non-LAD lesions was performed by an interventional cardiologist with a standardized technique through the femoral artery.

Before the procedure, clopidogrel was stopped for at least 7 days, whereas aspirin $100 \mathrm{mg} /$ day was maintained. During the surgery, unfractionated heparin was administrated intravenously before LIMA harvesting to achieve a kaolin-based activated clotting time (ACT) $>300$ seconds, and reserved with protamine sulfate when the LIMA-LAD anastomosis was successfully completed. For PCI, a loading dose of $300 \mathrm{mg}$ clopidogrel was supplied through a nasogastric tube after confirming the LIMA-LAD graft patency with angiography, and additional unfractionated heparin was administered to achieve an ACT $>250$ seconds. After the procedure, clopidogrel $75 \mathrm{mg} /$ day was administered for at least $12 \mathrm{months}$, and aspirin $300 \mathrm{mg} /$ day for 1 month and $100 \mathrm{mg} /$ day thereafter for life was prescribed.

OPCAB was performed through median sternotomy, and the graft conduits were obtained by conventional methods. The distal anastomoses were performed on a beating heart with the aid of a coronary stabilizer, and the proximal anastomoses were performed using partial aortic occlusion clamps. During the surgery, unfractionated heparin was administrated intravenously before the LIMA harvest to maintain an ACT $>300$ seconds throughout the entire procedure, and protamine sulfate was used to reverse heparin when all anastomoses were completed. After the procedure, aspirin $100 \mathrm{mg} /$ day for life was prescribed. 


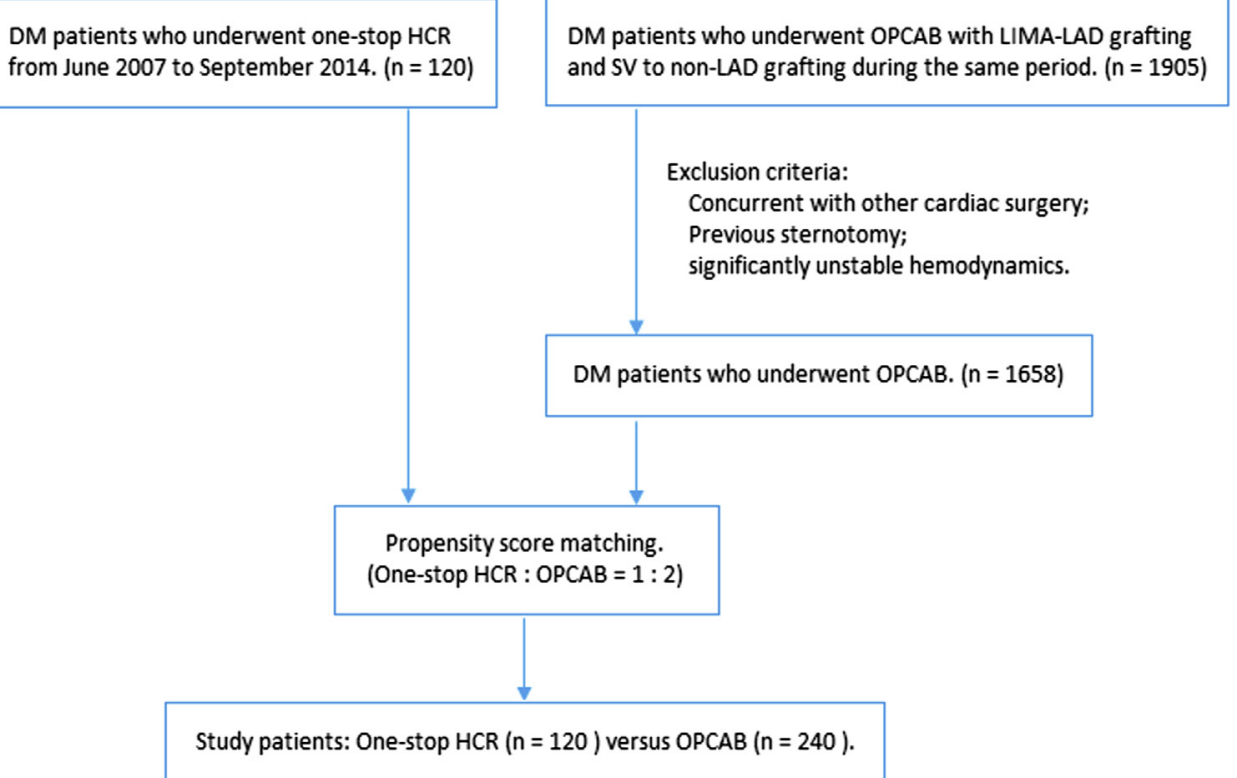

FIGURE 1. Flow chart of patient selection. $D M$, Diabetes mellitus; $H C R$, hybrid coronary revascularization; $O P C A B$, off-pump coronary artery bypass; LIMA, left internal mammary artery; $L A D$, left anterior descending artery; $S V$, saphenous vein.

\section{Study Endpoints}

The primary endpoint of this study was major adverse cardiac or cerebrovascular event (MACCE), a composite of all-cause death, myocardial infarction, stroke, and repeated revascularization, at the midterm followup. The second endpoints were postoperative in-hospital outcomes, including chest tube drainage, blood transfusion, mechanical ventilation time, length of intensive care unit stay, and length of hospital stay.

\section{Follow-up}

As part of institutional standard procedures, all postoperative patients were scheduled to return for an outpatient follow-up at 6 months after discharge and then once every year thereafter. The research staff would check the hospital database annually to complete any routine follow-up information by telephone or mail with standard forms.

\section{Statistics}

Propensity score matching. The propensity score was estimated by a logistic regression model in which one-stop HCR or OPCAB ( 1 or 0 ) was regressed on selected baseline variables. Referring to previous studies, ${ }^{12,14,15}$ the baseline variables that had an important impact on outcomes were included in the propensity score model. These variables included sex, age, body mass index, hypertension, hyperlipidemia, DM on insulin therapy, preoperative myocardial infarction, left main coronary artery disease, number of diseased vessels, left ventricular ejection fraction, renal dysfunction, and chronic lung disease (Table 1). The remaining baseline variables were also collected and compared between the 2 groups after propensity score matching (Table 2). A predesigned SAS macro for $5 \rightarrow 1$ digit greedy matching without replacement was used to perform the 1:2 match. Balance in baseline variables was assessed using the standardized difference (SD), of which a value $<10$ is considered to indicate good balance between the 2 groups. ${ }^{16}$

Statistical methods for outcomes. Data are expressed as mean \pm standard deviation, median (interquartile range [IQR]), or number $(\%)$. Accounting for the matched-pairs design, the survival analysis was evaluated with a marginal Cox model, and the continuous and dichotomous variables of the in-hospital outcomes were statistically compared using the
Wilcoxon signed-rank test and a logistic regression model using generalized estimating equations, respectively. ${ }^{17,18} \mathrm{~A} P$ value $<.05$ was considered statistically significant.

Statistical analyses were performed with SAS version 9.4 (SAS Institute, Cary, NC).

\section{RESULTS}

Propensity Score Matching

Each of the 120 patients with DM who underwent one-stop HCR was successfully matched with 2 patients with DM who underwent OPCAB. Every baseline variable

TABLE 1. Baseline variables selected for the propensity score matching model

\begin{tabular}{lccc}
\hline \multicolumn{1}{c}{ Variable } & $\begin{array}{c}\text { HCR } \\
(\mathbf{n}=\mathbf{1 2 0})\end{array}$ & $\begin{array}{r}\text { OPCAB } \\
(\mathbf{n}=\mathbf{2 4 0})\end{array}$ & SD $^{*}$ \\
\hline Female sex, n (\%) & $23(19.2)$ & $49(20.4)$ & 3.1 \\
Age, year, mean \pm SD & $62.3 \pm 9.4$ & $62.8 \pm 8.4$ & 6.2 \\
BMI, mean \pm SD & $25.6 \pm 3.0$ & $25.5 \pm 2.9$ & 3.2 \\
Hypertension, n (\%) & $88(73.3)$ & $178(74.2)$ & 1.9 \\
Hyperlipidemia, n (\%) & $96(80.0)$ & $193(80.4)$ & 1.1 \\
Diabetes mellitus on & $57(47.5)$ & $116(48.3)$ & 1.7 \\
$\quad$ insulin therapy, n (\%) & & & \\
Myocardial infarction, n (\%) & $39(32.5)$ & $75(31.3)$ & 2.7 \\
LM, n (\%) & $41(34.2)$ & $87(36.3)$ & 4.4 \\
Number of diseased vessels, & $2.7 \pm 0.5$ & $2.7 \pm 0.5$ & 5.3 \\
$\quad$ mean \pm SD & & & \\
LVEF, mean \pm SD & $63.9 \pm 7.3$ & $64.2 \pm 6.9$ & 4.0 \\
Renal dysfunction, n (\%) & $2(1.7)$ & $4(1.7)$ & 0 \\
Chronic lung disease, n $(\%)$ & $2(1.7)$ & $3(1.3)$ & 3.5 \\
\hline
\end{tabular}

$H C R$, Hybrid coronary revascularization; $O P C A B$, off-pump coronary artery bypass grafting; $S D$, standardized difference; $B M I$, body mass index; $L M$, left main coronary artery $\geq 50 \%$ narrowing preoperatively; $L V E F$, left ventricular ejection fraction. *A value $<10$ is considered to indicate good balance between the 2 groups. 
TABLE 2. Baseline variables not included in the propensity score matching model

\begin{tabular}{lccc}
\hline \multicolumn{1}{c}{ Variable } & $\begin{array}{c}\text { HCR } \\
(\mathbf{n}=\mathbf{1 2 0})\end{array}$ & $\begin{array}{c}\text { OPCAB } \\
(\mathbf{n}=\mathbf{2 4 0})\end{array}$ & SD $^{*}$ \\
\hline Current smoker, n (\%) & $48(40.0)$ & $99(41.3)$ & 2.5 \\
Cerebrovascular disease, n (\%) & $16(13.3)$ & $28(11.7)$ & 5.0 \\
Extracardiac arteriopathy, n (\%) & $20(16.7)$ & $47(19.6)$ & 7.6 \\
Serum creatinine, $\mu$ mol/L, mean $\pm \mathrm{SD}$ & $81.4 \pm 17.1$ & $82.5 \pm 23.8$ & 5.3 \\
RCA, n (\%) & $109(90.8)$ & $214(89.2)$ & 5.5 \\
LAD, n (\%) & $120(100)$ & $240(100)$ & NA \\
LCX, n (\%) & $95(79.2)$ & $198(82.5)$ & 8.5 \\
\hline
\end{tabular}

$H C R$, Hybrid coronary revascularization; $O P C A B$, off-pump coronary artery bypass grafting; $S D$, standardized difference; $R C A$, right coronary artery system $\geq 50 \%$ narrowing of any vessel preoperatively; $L A D$, left anterior descending artery $\geq 50 \%$ narrowing preoperatively; $L C X$, left circumflex artery system $\geq 50 \%$ narrowing of any vessel preoperatively; $N A$, not applicable. ${ }^{*} \mathrm{~A}$ value $<10$ is considered to indicate good balance between the 2 groups.

entered into the propensity score model had good balance between the 2 matched groups (Table 1). Baseline variables not included in the model were also balanced between the 2 groups (Table 2).

\section{Procedure Characteristics}

Each of 120 DM patients who underwent one-stop HCR underwent simultaneous minimally invasive LIMA-LAD grafting and PCI for non-LAD lesions. The mean number of stents implanted per patient was $1.6 \pm 0.9$, and the mean length of implanted stents was $35.0 \pm 21.4 \mathrm{~mm}$ (original data in Table E2).

Each of the $240 \mathrm{DM}$ patients who underwent OPCAB underwent LIMA-LAD grafting and SV to non-LAD grafting. The mean number of non-LAD anastomoses per patient was $2.1 \pm 0.6$ (original data in Table E3).

\section{In-Hospital Outcomes}

Compared with OPCAB, one-stop HCR had less chest tube drainage within 24 hours (median, $573 \mathrm{~mL}$ [IQR, $320-835 \mathrm{~mL}$ ] vs $700 \mathrm{~mL}$ [IQR, 530-950 mL]; $P<.001$ ) and total chest tube drainage (median, $748 \mathrm{~mL}$ [IQR, 540-1080 mL] vs $990 \mathrm{~mL}$ [IQR, 730-1250 mL]; $P<.001)$. Correspondingly, the packed red blood cell transfusion rate was significantly lower in the one-stop HCR group $(18.3 \%$ vs $29.6 \% ; P=.032)$. However, there were no statistically significant between-group differences in the rates of plasma transfusion $(19.2 \%$ for one-stop HCR vs $22.1 \%$ for OPCAB; $P=.523$ ), any blood product transfusion $(29.2 \%$ vs $39.6 \% ; P=.076)$, and reoperation for controlling bleeding $(0.8 \%$ vs $2.5 \% ; P=.307)$. One-stop HCR was associated with a shorter mechanical ventilation time (median, 13.7 hours [IQR, 10.3-16.9 hours] vs 16.8 hours [IQR, 13.0-19.6 hours]; $P<.001$ ) and a shorter length of intensive care unit stay (median, 21.7 hours [IQR, 19.0-44.3 hours] vs 46.5 hours [IQR, 24.3-72.7 hours]; $P<.001$ ), but a similar length of hospital
TABLE 3. Postoperative in-hospital outcomes

\begin{tabular}{|c|c|c|c|}
\hline Variable & $\begin{array}{c}\text { HCR } \\
(n=120)\end{array}$ & $\begin{array}{c}\text { OPCAB } \\
(n=240)\end{array}$ & $\begin{array}{c}P \\
\text { value } \\
\end{array}$ \\
\hline $\begin{array}{l}\text { Chest tube drainage within } \\
24 \text { hours, mL, median } \\
\text { (IQR) }\end{array}$ & $573(320-835)$ & $700(530-950)$ & $<.001$ \\
\hline $\begin{array}{l}\text { Total chest tube drainage, } \\
\text { mL, median (IQR) }\end{array}$ & $748(540-1080)$ & $990(730-1250)$ & $<.001$ \\
\hline $\begin{array}{l}\text { Transfusion of packed } \\
\text { RBCs, n (\%) }\end{array}$ & $22(18.3)$ & $71(29.6)$ & .032 \\
\hline Transfusion of plasma, n (\%) & $23(19.2)$ & $53(22.1)$ & .523 \\
\hline $\begin{array}{l}\text { Transfusion of any blood } \\
\text { products, n }(\%)\end{array}$ & $35(29.2)$ & $95(39.6)$ & .076 \\
\hline $\begin{array}{l}\text { Reoperation for controlling } \\
\text { bleeding, } \mathrm{n}(\%)\end{array}$ & $1(0.8)$ & $6(2.5)$ & .307 \\
\hline $\begin{array}{l}\text { Mechanical ventilation time, } \\
\text { hour, median (IQR) }\end{array}$ & $13.7(10.3-16.9)$ & $16.8(13.0-19.6)$ & $<.001$ \\
\hline $\begin{array}{l}\text { Length of ICU stay, hour, } \\
\text { median (IQR) }\end{array}$ & $21.7(19.0-44.3)$ & $46.5(24.3-72.7)$ & $<.001$ \\
\hline $\begin{array}{l}\text { Length of hospital stay, day, } \\
\text { median (IQR) }\end{array}$ & $7(7-9)$ & $7(7-9)$ & 627 \\
\hline
\end{tabular}

stay (median, 7 days [IQR, 7-9 days] vs 7 days [IQR, 7-9 days]; $P=.627$ ) (Table 3).

\section{Midterm Outcomes}

By March 15, 2015, follow-up data were obtained from 120 patients $(100 \%)$ of the one-stop HCR group and 237 patients $(98.8 \%)$ of the OPCAB group. Over a median follow-up of more than 30 months (30.7 months [IQR, 22.4-52.6 months] vs 34.1 months [IQR, 20.0-43.5 months]; $P=.826$ ), the cumulative MACCE rates were similar in the one-stop HCR and OPCAB groups $(7.4 \%$ vs $8.0 \%$ at 3 years; hazard ratio [HR], 0.807; 95\% confidence limit [CL], 0.352-1.849; $P=.612$ ) (Figure 2). Mortality $(2.7 \%$ vs $2.8 \%$ at 3 years; HR, $1.000 ; 95 \%$ CL, $0.249-4.020$; $P=1.00)$, the rate of myocardial infarction $(0 \%$ vs $0.4 \%$ at 3 years; $P=.252$ ), and the rate of repeat revascularization $(4.7 \%$ vs $2.3 \%$ at 3 years; HR, $1.545 ; 95 \% \mathrm{CL}$, $0.452-5.286 ; P=.488$ ) were not statistically significantly different between the 2 groups; however, the stroke rate was significantly lower in the one-stop HCR group $(0 \%$ vs $3.6 \%$ at 3 years; $P=.046)$ (Table 4$)$.

\section{DISCUSSION}

HCR aims to accomplish complete revascularization with minimally invasive LIMA to LAD grafting and PCI for non-LAD lesions. ${ }^{19}$ One-stop HCR is performed in a state-of-the-art operation room, in which the coronary surgery and intervention are performed consecutively. ${ }^{20}$ Compared with staged HCR, in which the procedures are performed in different operative suites staged over days or even weeks, the simultaneous HCR eliminates logistic 


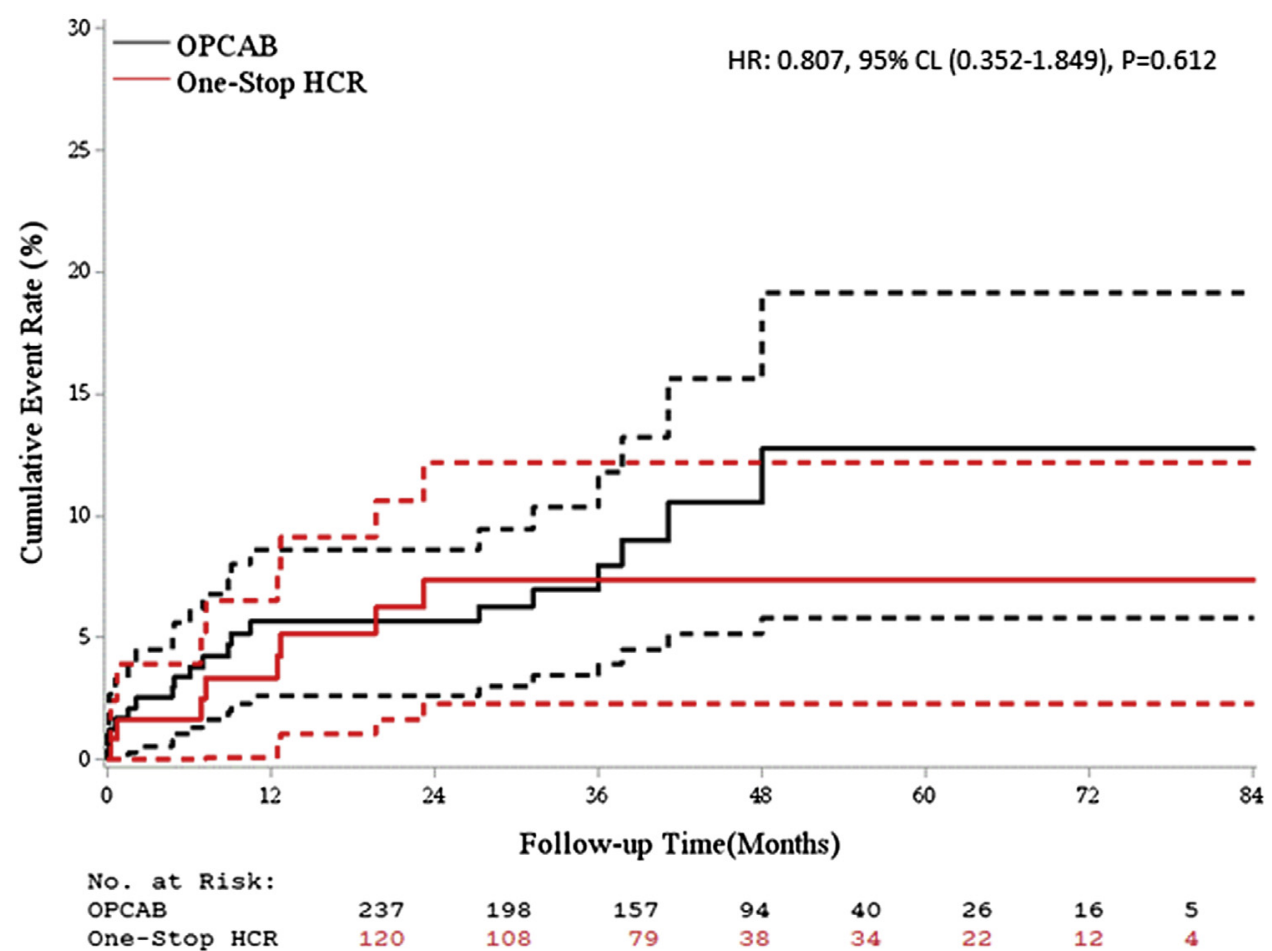

FIGURE 2. The MACCE Kaplan-Meier curves with number of patients at risk and $95 \%$ confidence limits. The HR was evaluated over a median follow-up of more than 30 months using a marginal Cox model. $O P C A B$, Off-pump coronary artery bypass; $H C R$, hybrid coronary revascularization; $H R$, hazard ratio; $C L$, confidence limit.

concerns about the timing and sequencing of separate procedures, and also minimizes the exposure to anesthesia and the inconvenience of transferring patients among different disciplines. In addition, the patency of the LIMA-LAD graft can be routinely assessed by instant angiography, and PCI is accomplished under the protection of the LIMA-LAD graft and in the presence of cardiac surgeons, and thus aggressive stenting is allowed. ${ }^{20}$ To our knowledge, this is by far the largest cohort of patients with DM undergoing one-stop HCR reported to date.

Patients with DM have more diffuse atherosclerosis and aggressive pathological progression, leading to a greater risk of restenosis and new stenosis after coronary revascularization. ${ }^{1}$ A recent randomized clinical trial found lower mortality and myocardial infarction rates for $\mathrm{CABG}$ compared with PCI in these patients. ${ }^{3}$ The LIMA-LAD graft is presumably essential to the survival superiority of CABG. ${ }^{4}$ One-stop HCR preserves LIMA-LAD grafting by means of minimally invasive strategies, and also routinely provides instant angiography to confirm graft patency. $^{20}$ Among patients undergoing one-stop HCR, 2 major defects $(1.7 \%)$, distal LIMA conduit stenosis and stenosis at the LIMA-LAD anastomosis, were detected in the LIMA-LAD grafts after intraoperative angiography. Both defects were corrected by immediate reoperation.

In this study, the similar midterm survival rate in the OPCAB and one-stop HCR groups $(2.7 \%$ vs $2.8 \%$ at 3 years; HR, 1.000; 95\% CL, 0.249-4.020; $P=1.00)$

TABLE 4. MACCE in the one-stop HCR and OPCAB groups

\begin{tabular}{|c|c|c|c|c|c|c|}
\hline \multirow[b]{2}{*}{ Variable } & \multirow[b]{2}{*}{$\operatorname{HCR}(n=120)$} & \multirow[b]{2}{*}{ OPCAB $(n=237)$} & \multirow[b]{2}{*}{ HR $(95 \%$ CL $)$} & \multicolumn{2}{|c|}{ Cumulative event rate at 3 years } & \multirow[b]{2}{*}{$P$ valu } \\
\hline & & & & HCR, \% & ОРСАВ, \% & \\
\hline Any MACCE, $n$ & 8 & 19 & $0.807(0.352-1.849)$ & 7.4 & 8.0 & .612 \\
\hline All-cause death, $\mathrm{n}$ & 3 & 6 & $1.000(0.249-4.020)$ & 2.7 & 2.8 & 1.000 \\
\hline Stroke, $\mathrm{n}$ & 0 & 8 & NA & 0 & 3.6 & $.046^{*}$ \\
\hline Myocardial infarction, $\mathrm{n}$ & 0 & 2 & NA & 0 & 0.4 & $.252 *$ \\
\hline Repeated revascularization, $\mathrm{n}$ & 5 & 6 & $1.545(0.452-5.286)$ & 4.7 & 2.3 & .488 \\
\hline Target lesion revascularization, $\mathrm{n}$ & 2 & 5 & $0.719(0.132-3.924)$ & 2.1 & 1.9 & .703 \\
\hline Follow-up time, months, median (IQR) & $30.7(22.4-52.6)$ & $34.1(20.0-43.5)$ & NA & NA & NA & .826 \\
\hline
\end{tabular}

$H C R$, Hybrid coronary revascularization; $O P C A B$, off-pump coronary artery bypass grafting; $H R$, hazard ratio; $C L$, confidence limits; $M A C C E$, major adverse cardiac and cerebrovascular events; $N A$, not applicable; $I Q R$, interquartile range. ${ }^{*}$ Log-rank test. 
may be attributed mainly to the high-quality LIMA-LAD graft. In addition, the rate of target lesion revascularization for PCI with DES has gradually decreased with improvements in stent materials and processes, ${ }^{21,22}$ and the rate is similar to the failure rate of saphenous grafts. ${ }^{10}$ Theoretically, by combining LIMA-LAD grafting and PCI with DES for non-LAD lesions, HCR may have a similar rate of repeat revascularization as conventional surgical revascularization in select patients. Our 30-month follow-up results showed similar rates of revascularization ( $4.7 \%$ for the one-stop HCR group vs $2.3 \%$ for the OPCAB group at 3 years; HR, $1.545 ; 95 \% \mathrm{CL}, 0.452-5.286$; $P=.488)$ and target lesion revascularization $(2.1 \%$ vs $1.9 \%$ at 3 years; $\mathrm{HR}, 0.719 ; 95 \% \mathrm{CL}, 0.132-3.924$; $P=.703)$.

One major disadvantage of CABG is a higher stroke incidence than that associated with PCI, especially in the early term, ${ }^{3,23}$ which is generally considered to be associated with cardiopulmonary bypass (CPB) and surgical procedures on the ascending aorta. ${ }^{24} \mathrm{By}$ avoiding the need for $\mathrm{CPB}$, OPCAB has the potential to reduce the incidence of stroke; however, the use of a partial aortic occlusion clamp may still increase the risk of stroke. ${ }^{25}$ Compared with OPCAB, HCR is totally absent from the aortic operation and may minimize the relevant risk of stroke. In addition, macroembolization and microembolization have been identified as major sources of stroke after cardiac surgeries. ${ }^{26}$ Therefore, dual antiplatelet strategy after one-stop HCR might play a potential role in the prevention of postoperative stroke. ${ }^{27}$ In this study, one-stop HCR was associated with a significantly lower stroke rate compared with OPCAB $(0 \%$ vs $3.6 \%$ at 3 years; $P=.046)$. Considering the more advanced and diffuse atherosclerotic plaque in the aorta and arteries of patients with DM, one-stop HCR is a promising alternative approach to revascularization for these patients.

Another major disadvantage of conventional surgical revascularization is the significant trauma, which is associated with an increased need for blood products and longer recovery time. ${ }^{28}$ Patients with DM experience more frequent complications with incision healing compared with patients without DM. ${ }^{29}$ One-stop HCR not only involves minor surgical trauma with minimally invasive LIMA-LAD grafting and less-invasive PCI for non-LAD lesions, but also diminishes the risk of perioperative bleeding through the use of a modified antiplatelet and anticoagulation protocol. $^{30}$ In this study, one-stop HCR was associated with less chest tube drainage, a lower packed red blood cell transfusion rate, and faster recovery compared with OPCAB. Thus, one-stop HCR provides an attractive revascularization option for patients unfavorable for median sternotomy, extensive skin incision, or $\mathrm{CPB}$, including selected patients with DM.
This study has several limitations. First, this was a retrospective study from a single center. The relatively small sample size and short follow-up time may weaken the force of our statistical analyses. Randomized clinical trials with long-term follow-up comparing one-stop HCR and $\mathrm{OPCAB}$ are expected. Second, there might be a bias in terms of unknown confounding factors, although our use of propensity score matching simulated randomized progress with regard to the important prognostic impactors. Third, the dual antiplatelet therapy in the one-stop HCR group might have played a role in the prevention of postoperative stroke; nevertheless, there remains no evidence of the efficacy of widespread use of long-term aspirin with clopidogrel for the secondary prevention of ischemic stroke.

\section{CONCLUSIONS}

In selected patients with $\mathrm{DM}$ and multivessel CAD, one-stop HCR decreased perioperative invasiveness and was associated with similar and favorable midterm outcomes compared with OPCAB. One-stop HCR may be a safe and reproducible alternative for this cohort of patients.

\section{Conflict of Interest Statement}

Authors have nothing to disclose with regard to commercial support.

We thank Dr Hongqiu Gu, Department of Statistics, Fuwai Hospital, for his contribution to the statistical work in this study.

\section{References}

1. Rydén L, Grant PJ, Anker SD, Berne C, Cosentino F, Danchin N, et al. ESC guidelines on diabetes, pre-diabetes, and cardiovascular diseases developed in collaboration with the EASD: the task force on diabetes, pre-diabetes, and cardiovascular diseases of the European Society of Cardiology (ESC) and developed in collaboration with the European Association for the Study of Diabetes (EASD). Eur Heart J. 2013;34:3035-87.

2. Hlatky MA, Boothroyd DB, Bravata DM, Boersma E, Booth J, Brooks MM, et al. Coronary artery bypass surgery compared with percutaneous coronary interventions for multivessel disease: a collaborative analysis of individual patient data from ten randomised trials. Lancet. 2009;373:1190-7.

3. Farkouh ME, Domanski M, Sleeper LA, Siami FS, Dangas G, Mack M, et al. Strategies for multivessel revascularization in patients with diabetes. $N$ Engl J Med. 2012;367:2375-84.

4. Loop FD, Lytle BW, Cosgrove DM, Stewart RW, Goormastic M, Williams GW, et al. Influence of the internal-mammary-artery graft on 10-year survival and other cardiac events. N Engl J Med. 1986;314:1-6.

5. Tatoulis J, Buxton BF, Fuller JA. Patencies of 2127 arterial to coronary conduits over 15 years. Ann Thorac Surg. 2004;77:93-101.

6. Sabik JF III, Lytle BW, Blackstone EH, Houghtaling PL, Cosgrove DM. Comparison of saphenous vein and internal thoracic artery graft patency by coronary system. Ann Thorac Surg. 2005;79:544-51.

7. Fitzgibbon GM, Kafka HP, Leach AJ, Keon WJ, Hooper GD, Burton JR. Coronary bypass graft fate and patient outcome: angiographic follow-up of 5,065 grafts related to survival and reoperation in 1,388 patients during 25 years. J Am Coll Cardiol. 1996;28:616-26.

8. Holmes DR Jr, Leon MB, Moses JW, Popma JJ, Cutlip D, Fitzgerald PJ, et al. Analysis of 1-year clinical outcomes in the SIRIUS trial: a randomized trial of a sirolimus-eluting stent versus a standard stent in patients at high risk for coronary restenosis. Circulation. 2004;109:634-40. 
9. Weisz G, Leon MB, Holmes DR Jr, Kereiakes DJ, Popma JJ, Teirstein PS, et al. Five-year follow-up after sirolimus-eluting stent implantation results of the SIRIUS (Sirolimus-Eluting Stent in De-Novo Native Coronary Lesions) Trial. J Am Coll Cardiol. 2009;53:1488-97.

10. Byrne JG, Leacche M, Vaughan DE, Zhao DX. Hybrid cardiovascular procedures. JACC Cardiovasc Interv. 2008;1:459-68.

11. Panoulas VF, Colombo A, Margonato A, Maisano F. Hybrid coronary revascularization: promising, but yet to take off. J Am Coll Cardiol. 2015;65:85-97.

12. Hu S, Li Q, Gao P, Xiong H, Zheng Z, Li L, et al. Simultaneous hybrid revascularization versus off-pump coronary artery bypass for multivessel coronary artery disease. Ann Thorac Surg. 2011;91:432-8.

13. Halkos ME, Vassiliades TA, Douglas JS, Morris DC, Rab ST, Liberman HA, et al. Hybrid coronary revascularization versus off-pump coronary artery bypass grafting for the treatment of multivessel coronary artery disease. Ann Thorac Surg. 2011;92:1695-701.

14. Shen L, Hu S, Wang H, Xiong H, Zheng Z, Li L, et al. One-stop hybrid coronary revascularization versus coronary artery bypass grafting and percutaneous coronary intervention for the treatment of multivessel coronary artery disease: 3-year follow-up results from a single institution. J Am Coll Cardiol. 2013;61: 2525-33.

15. Zhou S, Fang Z, Xiong H, Hu S, Xu B, Chen L, et al. Effect of one-stop hybrid coronary revascularization on postoperative renal function and bleeding: a comparison study with off-pump coronary artery bypass grafting surgery. J Thorac Cardiovasc Surg. 2014;147:1511-6.e1.

16. Austin PC, Grootendorst P, Anderson GM. A comparison of the ability of different propensity score models to balance measured variables between treated and untreated subjects: a Monte Carlo study. Stat Med. 2007;26:734-53.

17. Austin PC. Propensity-score matching in the cardiovascular surgery literature from 2004 to 2006: a systematic review and suggestions for improvement. J Thorac Cardiovasc Surg. 2007;134:1128-35.

18. Lee EW, Wei LJ, Amato DA. Cox-type regression analysis for large numbers of small groups of correlated failure time observations. In: Klein JP, Goel PK, eds. Survival Analysis: State of the Art. Dordrecht: Kluwer Academic; 1992: $237-47$.

19. Angelini GD, Wilde P, Salerno TA, Bosco G, Calafiore AM. Integrated left small thoracotomy and angioplasty for multivessel coronary artery revascularisation. Lancet. 1996;347:757-8.
20. Hu S, Gao R. Hybrid coronary revascularization for multivessel coronary artery disease. Coron Artery Dis. 2014;25:258-65.

21. Harskamp RE, Park DW. Percutaneous coronary intervention in diabetic patients: should choice of stents be influenced? Expert Rev Cardiovasc Ther. 2013;11: 541-53.

22. Garg S, Serruys PW. Coronary stents: current status. J Am Coll Cardiol. 2010 56(10 Suppl):S1-42.

23. Serruys PW, Morice MC, Kappetein AP, Colombo A, Holmes DR, Mack MJ, et al. Percutaneous coronary intervention versus coronary-artery bypass grafting for severe coronary artery disease. N Engl J Med. 2009; 360:961-72.

24. Head SJ, Kieser TM, Falk V, Huysmans HA, Kappetein AP. Coronary artery bypass grafting, part 1: the evolution over the first 50 years. Eur Heart $J$ 2013;34:2862-72.

25. Lev-Ran O, Braunstein R, Sharony R, Kramer A, Paz Y, Mohr R, et al. No-touch aorta off-pump coronary surgery: the effect on stroke. J Thorac Cardiovasc Surg. 2005; 129:307-13.

26. Gottesman RF, Sherman PM, Grega MA, Yousem DM, Borowicz LM Jr, Selnes OA, et al. Watershed strokes after cardiac surgery: diagnosis, etiology, and outcome. Stroke. 2006;37:2306-11.

27. Davis KA, Miyares MA, Dietrich E. Dual antiplatelet therapy with clopidogre and aspirin after ischemic stroke: a review of the evidence. Am J Health Syst Pharm. 2015;72:1623-9.

28. Head SJ, Börgermann J, Osnabrugge RL, Kieser TM, Falk V, Taggart DP, et al Coronary artery bypass grafting, part 2: optimizing outcomes and future prospects. Eur Heart J. 2013;34:2873-86.

29. Carson JL, Scholz PM, Chen AY, Peterson ED, Gold J, Schneider SH Diabetes mellitus increases short-term mortality and morbidity in patient undergoing coronary artery bypass graft surgery. J Am Coll Cardiol. 2002;40: 418-23.

30. Gao P, Xiong H, Zheng Z, Li L, Gao R, Hu SS. Evaluation of antiplatelet effects of a modified protocol by platelet aggregation in patients undergoing "one-stop" hybrid coronary revascularization. Platelets. 2010;21:183-90.

Key Words: one-stop hybrid coronary revascularization, off-pump coronary artery bypass, diabetes mellitus

Readers who found these articles interesting may also like to read the following papers found in recent and future issues of our sister publications, Seminars in Thoracic and Cardiovascular Surgery and Operative Techniques in Thoracic and Cardiovascular Surgery!

\section{Acquired: Coronary Artery Disease}

Original Submissions: Micromorphology of Skeletonized and Pedicled Internal Thoracic and Radial Arteries. Sergey Mamchur. Semin Thorac Cardiovasc Surg 2015; Summer; 27(2):115-120.

Editorial Commentary: Harvesting Arterial Grafts: Barebones or More. Faisal G. Bakaeen. Semin Thorac Cardiovasc Surg 2015; 27(2):121-122. 
TABLE E1. Preoperative variables before matching

\begin{tabular}{lccr}
\hline \multicolumn{1}{c}{ Variable } & $\begin{array}{c}\text { HCR } \\
(\mathbf{n}=\mathbf{1 2 0})\end{array}$ & $\begin{array}{c}\text { OPCAB } \\
(\mathbf{n}=\mathbf{1 6 5 8})\end{array}$ & \multicolumn{1}{c}{ SD } \\
\hline Female sex, n (\%) & $23(19.2)$ & $445(26.8)$ & 18.3 \\
Age, year, mean \pm SD & $62.3 \pm 9.4$ & $61.6 \pm 8.4$ & 7.1 \\
BMI, mean \pm SD & $25.6 \pm 3.0$ & $25.6 \pm 3.0$ & 0.5 \\
Hypertension, n (\%) & $88(73.3)$ & $1314(79.3)$ & 14.0 \\
Hyperlipidemia, n (\%) & $96(80.0)$ & $1210(73.0)$ & 16.6 \\
Diabetes mellitus & $57(47.5)$ & $626(37.8)$ & 19.8 \\
$\quad$ on insulin, n (\%) & & & \\
Myocardial infarction, n (\%) & $39(32.5)$ & $526(31.7)$ & 1.7 \\
LM, n (\%) & $41(34.2)$ & $430(25.9)$ & 18.0 \\
Number of diseased & $2.7 \pm 0.5$ & $2.8 \pm 0.4$ & 23.0 \\
$\quad$ vessels, mean \pm SD & & & \\
LVEF, mean \pm SD & $63.9 \pm 7.3$ & $60.0 \pm 8.6$ & 48.9 \\
Renal dysfunction, n (\%) & $2(1.7)$ & $22(1.3)$ & 2.8 \\
Chronic lung disease, $\mathrm{n}(\%)$ & $2(1.7)$ & $12(0.7)$ & 8.8 \\
Current smoker, n $(\%)$ & $48(40.0)$ & $812(49.0)$ & 18.1 \\
Cerebrovascular disease, $\mathrm{n}(\%)$ & $16(13.3)$ & $166(10.0)$ & 10.4 \\
Extracardiac arteriopathy, $\mathrm{n}(\%)$ & $20(16.7)$ & $248(15.0)$ & 4.8 \\
Serum creatinine, mean $\pm \mathrm{SD}$ & $81.4 \pm 17.1$ & $80.6 \pm 21.8$ & 4.2 \\
RCA, n (\%) & $109(90.8)$ & $1455(87.8)$ & 9.9 \\
LAD, n (\%) & $120(100)$ & $1644(99.2)$ & 13.0 \\
LCX, n (\%) & $95(79.2)$ & $1449(87.4)$ & 22.2 \\
\hline
\end{tabular}

$H C R$, Hybrid coronary revascularization; $O P C A B$, off-pump coronary artery bypass grafting; $S D$, standardized difference; $B M I$, body mass index; $L M$, left main coronary artery $\geq 50 \%$ narrowing preoperatively; $L V E F$, left ventricular ejection fraction; $R C A$, right coronary artery system $\geq 50 \%$ narrowing of any vessel preoperatively; $L A D$, left anterior descending artery $\geq 50 \%$ narrowing preoperatively; $L C X$, left circumflex artery system $\geq 50 \%$ narrowing of any vessel preoperatively.
TABLE E2. Procedural characteristics in the one-stop HCR group $(\mathbf{n}=\mathbf{1 2 0})$

\begin{tabular}{|c|c|}
\hline Characteristic & Value \\
\hline LIMA-LAD grafting, $\mathrm{n}(\%)$ & $120(100)$ \\
\hline PCI for non-LAD, $\mathrm{n}(\%)$ & $120(100)$ \\
\hline Drug-eluting stents, $\mathrm{n}(\%)$ & $119(99.2)$ \\
\hline Bare metal stents, $\mathrm{n}(\%)$ & $1(0.8)$ \\
\hline Stented lesions, $\mathrm{n}$ & 165 \\
\hline $\mathrm{LM}, \mathrm{n}(\%)$ & $27(16.4)$ \\
\hline LAD system, n (\%) & $3(1.8)$ \\
\hline DA & 3 \\
\hline LCX system, n (\%) & $59(35.6)$ \\
\hline LCX & 50 \\
\hline $\mathrm{OM}$ & 9 \\
\hline RCA system, n (\%) & $76(46.1)$ \\
\hline RCA, n & 67 \\
\hline PDA, $n$ & 6 \\
\hline LVB, $n$ & 3 \\
\hline Stents, $\mathrm{n}$ & 196 \\
\hline Drug-eluting stents, $\mathrm{n}(\%)$ & 195 (99.5) \\
\hline Paclitaxel-eluting stents, $\mathrm{n}(\%)$ & $7(3.6)$ \\
\hline Sirolimus-eluting stents, $\mathrm{n}(\%)$ & $131(67.2)$ \\
\hline Zotarolimus-eluting stents, n (\%) & $33(16.9)$ \\
\hline Everolimus-eluting stents, $\mathrm{n}(\%)$ & $24(12.3)$ \\
\hline Bare metal stents, n (\%) & $1(0.5)$ \\
\hline Stents per patient, mean \pm SD & $1.6 \pm 0.9$ \\
\hline Total stents length per patient, mm, mean \pm SD & $35.0 \pm 21.4$ \\
\hline
\end{tabular}

TABLE E3. Procedural characteristics in the OPCAB group

\begin{tabular}{lc}
\hline \multicolumn{1}{c}{ Characteristic } & OPCAB $(\mathbf{n}=\mathbf{2 4 0})$ \\
\hline LIMA-LAD grafting, n (\%) & $240(100)$ \\
Non-LAD grafting, n (\%) & $240(100)$ \\
AA-SV-non-LAD grafting, n (\%) & $240(100)$ \\
Distal anastomoses of non-LAD grafting, n & 512 \\
LAD system, n (\%) & $137(26.8)$ \\
DA, n & 112 \\
IM, n & 25 \\
LCX system, n (\%) & $190(37.1)$ \\
LCX, n & 17 \\
OM, n & 173 \\
RCA system, n (\%) & $185(36.1)$ \\
RCA, n & 33 \\
PDA, n & 120 \\
LVB, n & 32 \\
Anastomoses of non-LAD per patient, mean \pm SD & $2.1 \pm 0.6$ \\
\hline$O P C A B$, Off-pump coronary artery bypass grafting; LIMA, left internal mammary \\
artery; $L A D$, left anterior descending artery; $A A$, ascending aorta; $S V$, saphenous \\
vein; non- $L A D$, coronary arteries other than left anterior descending artery; \\
$D A$, diagonal artery; $I M$, intermediate artery; $L C X$, left circumflex artery; $O M$, obtuse \\
marginal branch; $R C A$, right coronary artery; $P D A$, posterior descending artery; \\
$L V B$, left ventricular branch.
\end{tabular}

